\title{
Effect of drying methods on the microstructures and properties of cured calcium aluminate cement pastes
}

\author{
Zhongfeng XIA ${ }^{1}$, Zhoufu WANG ${ }^{1 \dagger}$, Yan MA ${ }^{1}$, Hao LIU ${ }^{1}$ and Xitang WANG ${ }^{1}$ \\ ${ }^{1}$ The State Key Laboratory of Refractories and Metallurgy, Wuhan University of Science and Technology, \\ Wuhan, Hubei, 430081, PR China
}

\begin{abstract}
Drying process is necessary in the preparation and application of refractory castables. In this work, the effects of conventional drying, microwave drying and freeze drying on the composition and properties of cured calcium aluminate cement (CAC) pastes were comparatively investigated. The differences in the microstructures evolution process under various drying mechanisms were discussed. The results show that metastable $\mathrm{CAH}_{10}$ and $\mathrm{C}_{2} \mathrm{AH}_{8}$ are completely transformed into stable phases in the conventional dried pastes, while a small amount of flaky $\mathrm{C}_{2} \mathrm{AH}_{8}$ remained in pastes dried via microwave. Nevertheless, the major hydrates in the freeze-dried pastes are $\mathrm{CAH}_{10}$ and $\mathrm{C}_{2} \mathrm{AH}_{8}$. In addition, the pores in pastes dried by microwave are mainly distributed in the range of 20-2000 $\mathrm{nm}$, while the freeze-dried pastes contain more gel pores and show higher elastic modulus. A new approach to effectively regulate the pore structure of $\mathrm{CAC}$ bonded materials via non-conventional drying methods is proposed in the present work.
\end{abstract}

(C2021 The Ceramic Society of Japan. All rights reserved.

Key-words: Calcium aluminate cement, Microwave drying, Freeze drying, Hydration product, Pore size distribution

[Received July 19, 2021; Accepted August 24, 2021]

\section{Introduction}

Calcium aluminate cements (CAC), as a commonly used hydraulic binders in refractory castables, are characterized by high strength in the early stage and high temperature resistance. ${ }^{1-4)}$ Usually, there are several hydration products generated in CAC bonded refractory castables with different curing conditions (temperature, humidity, time), mainly including $\mathrm{CAH}_{10}\left(\mathrm{CaO} \cdot \mathrm{Al}_{2} \mathrm{O}_{3} \cdot 10 \mathrm{H}_{2} \mathrm{O}\right)$, $\mathrm{C}_{2} \mathrm{AH}_{8}\left(2 \mathrm{CaO} \cdot \mathrm{Al}_{2} \mathrm{O}_{3} \cdot 8 \mathrm{H}_{2} \mathrm{O}\right), \mathrm{C}_{3} \mathrm{AH}_{6}\left(3 \mathrm{CaO} \cdot \mathrm{Al}_{2} \mathrm{O}_{3} \cdot 6 \mathrm{H}_{2} \mathrm{O}\right)$ and $\mathrm{AH}_{3}\left(\mathrm{Al}_{2} \mathrm{O}_{3} \cdot 3 \mathrm{H}_{2} \mathrm{O}\right.$, gibbsite or gel form), among which $\mathrm{CAH}_{10}, \mathrm{C}_{2} \mathrm{AH}_{8}$ and $\mathrm{AH}_{x}$ gel known as metastable phases are thermodynamically unstable. ${ }^{5)-9)}$ The hydration products are in the shape of sheets, needles or columns, and interlaced with each other to form a network structure. A large number of gels fill in the pores of the network to form a cement bonding matrix with compact structure in low porosity, which makes the castables obtain a higher bonding strength. ${ }^{7), 17)} \mathrm{CAC}$ bonded castables need to be dried to prevent a large amount of water evaporation in the high temperature application, which will further increase steam pressure inside the materials, cause the castables to burst and then lead to structural damage. 1),7),8)

CAC bonded castables are often dried by means of electric furnace or hot air in the laboratory and industry.

† Corresponding author: Z. Wang; E-mail: whwangzf@163. com, whwangzf@126.com
Many results have shown that the drying process has a great influence on the phase composition and microstructure of the castables. ${ }^{5)-13)}$ During the drying process, metastable $\mathrm{CAH}_{10}, \mathrm{C}_{2} \mathrm{AH}_{8}$ and $\mathrm{AH}_{x}$ gel may transform to stable $\mathrm{C}_{3} \mathrm{AH}_{6}$ and $\mathrm{AH}_{3}$ with the increase of temperature or time. ${ }^{13), 16)}$ Because the density of $\mathrm{CAH}_{10}$ and $\mathrm{C}_{2} \mathrm{AH}_{8}$ is lower than that of $\mathrm{C}_{3} \mathrm{AH}_{6}$ and $\mathrm{AH}_{3}$, the transformation from metastable phases to stable ones leads to the increase of pores inside the castables, resulting in the volume shrinkage of the materials. ${ }^{6-11)}$ The hydration products decompose gradually with the increase of treated temperature, but the hydrates crystal forms remain unchanged after being heated at a certain temperature. According to own investigations the crystal shapes of the primarily formed crystals are preserved even at high temperatures, because the reaction kinetic is hampered at the ambient conditions that prevail during drying. ${ }^{17)}$ Thus, the variations of phase composition and microstructure of the cured castables during drying process affect the pore structure of the castables in the practical application. ${ }^{16)-20)}$ It has to be noted that the pore structure of the castables has a great correlation with strength and corrosion resistance. ${ }^{14), 15), 33)}$ Therefore, it is very important to control the phase composition and pore structure of castables during drying process. In recent decades, a lot of researches have been conducted on various drying methods. ${ }^{18)-23)}$ Among them, microwave drying can achieve uniform and quick heating of the whole material. Heat is produced by violent 
movement of water molecules subjected to high-frequency microwave during microwave drying, achieving high heating efficiency and short drying time. ${ }^{20), 22), 23)}$ The drying method has been used to reduce the drying time and cut energy consumption. ${ }^{34)}$ Freeze drying is an effective method to remove water in the material at a low temperature. The free water condenses into ice and then sublimate directly in vacuum environment during the drying process. Thus, the whole freeze drying process has little influence on the composition and structure of the dried materials. ${ }^{6), 11)}$

In this work, the effects of microwave and freeze drying on the microstructures and properties of cured CAC pastes were investigated compared with conventional drying process. The composition of dried cement pastes, microscopic morphology of hydration products and physical properties were analyzed. Besides, the microstructure evolution process of the cured CAC pastes under different drying mechanism was discussed.

\section{Experimental}

\subsection{Raw material}

The CAC used in this work was Secar71 cement produced by Kerneos Company. The chemical and phase composition of CAC is shown in Table 1.

\subsection{Sample preparation}

The CAC pastes were prepared with a water-to-cement ratio of 0.3 to achieve standard consistency. The raw materials were mixed in a mortar mixer adopted revolution and rotation synchronous agitation modes. Dry mixing was carried out at revolution velocity $60 \mathrm{rpm}$ and rotation velocity $140 \mathrm{rpm}$ for $1 \mathrm{~min}$, while wet mixing was conducted at revolution velocity $120 \mathrm{rpm}$ and rotation velocity $280 \mathrm{rpm}$ for $3 \mathrm{~min}$. The pastes were cast in the shape of bars $(25 \mathrm{~mm} \times 25 \mathrm{~mm} \times 140 \mathrm{~mm})$ by vibration. In order to prevent drying out and carbonation of the samples during curing, the surface of the mold was covered with a plastic film after casting. The samples were cured at $25^{\circ} \mathrm{C}$ and $90 \%$ R. H. in a constant temperature and humidity chamber for $24 \mathrm{~h}$, then demolded and dried by the following three methods.

(1) Oven drying, the samples were dried in an electric drying oven at $110^{\circ} \mathrm{C}$ for $24 \mathrm{~h}$.

(2) Freeze drying, the samples were frozen in a refrigerator at $-30^{\circ} \mathrm{C}$ for $48 \mathrm{~h}$, and then dried at room temperature (about $25^{\circ} \mathrm{C}$ ) in the freeze dryer with a cold trap temperature of $-50{ }^{\circ} \mathrm{C}$ and a vacuum of $5 \mathrm{~Pa}$ for $24 \mathrm{~h}$.

(3) Microwave drying, the samples were dried in a small industrial microwave oven with $500 \mathrm{~W}$ powers for $5 \mathrm{~min}$ to make sure free water was removed in quite a short time.

Table 1. Chemical and phase compositions of Secar71 cement

\begin{tabular}{cccccccc}
\hline \multicolumn{3}{c}{ Chemical composition (wt.\%) } & & \multicolumn{3}{c}{ Phase composition (wt.\%) } \\
\cline { 1 - 3 } $\mathrm{Al}_{2} \mathrm{O}_{3}$ & $\mathrm{CaO}$ & $\mathrm{SiO}_{2}$ & $\mathrm{~K}_{2} \mathrm{O}+\mathrm{Na}_{2} \mathrm{O}$ & & $\mathrm{CA}$ & $\mathrm{CA}_{2}$ & $\mathrm{C}_{12} \mathrm{~A}_{7}$ \\
\hline 69.63 & 29.68 & 0.22 & 0.26 & & 59.06 & 35.95 & 0.30 \\
\hline
\end{tabular}

The samples were prepared in a single batch to make sure the drying experiments are comparable and the hydration degree of CAC is the same. The experimental materials and instruments were kept in a constant temperature room of $25^{\circ} \mathrm{C}$ for $24 \mathrm{~h}$ before mixing. The dried samples were kept in a vacuum desiccator filled with silicone before test.

\subsection{Testing and characterization methods}

Phase composition of the dried pastes was determined using X-ray diffractive analyzer (X'Pert Pro, Philips), and the diffraction spectra of $2 \theta$ range of $5-50^{\circ}$ was collected. Fourier transform infrared spectroscopy (FTIR) of the pastes was tested using an Infrared Spectrometer (Equinoxss/Hyperion 2000 System, Bruker, Germany). TG-DSC analyses were also carried out with a comprehensive thermal analyzer (Netzsch STA 449C, Germany) at a heating rate of $10^{\circ} \mathrm{C} / \mathrm{min}$ between 30 and $1000^{\circ} \mathrm{C}$ in an air flow.

Microstructure of the dried pastes was characterized by a field emission scanning electron microscopy (Nova 400 Nano SEM, FEI) with energy dispersive spectroscopy (EDS) (INCA, IE350 Penta FETX-3, Oxford), and the fracture surface of the samples was tested. The acceleration voltage of the beam was $15 \mathrm{kV}$. Pore size distribution was evaluated by a mercury intrusion porosimeter (Autopore IV9500). The samples were prepared into pieces about $10 \mathrm{~mm}$ and the pressure range was set to 30-60,000 psia.

Elastic modulus of the dried samples at room temperature was tested in accordance with the standard method (ISO12680-1). Additionally, the apparent porosity of the dried samples was measured by the Archimedes method (ISO5017), using kerosene as the immersion liquid.

\section{Results and discussion}

\subsection{Phase composition of pastes treated by different drying methods}

The X-ray diffraction (XRD) patterns of pastes treated by different drying methods are shown in Fig. 1. It can be known that pastes treated by three drying methods all contain anhydrous phases $\mathrm{CA}$ and $\mathrm{CA}_{2}$. There are diffrac-

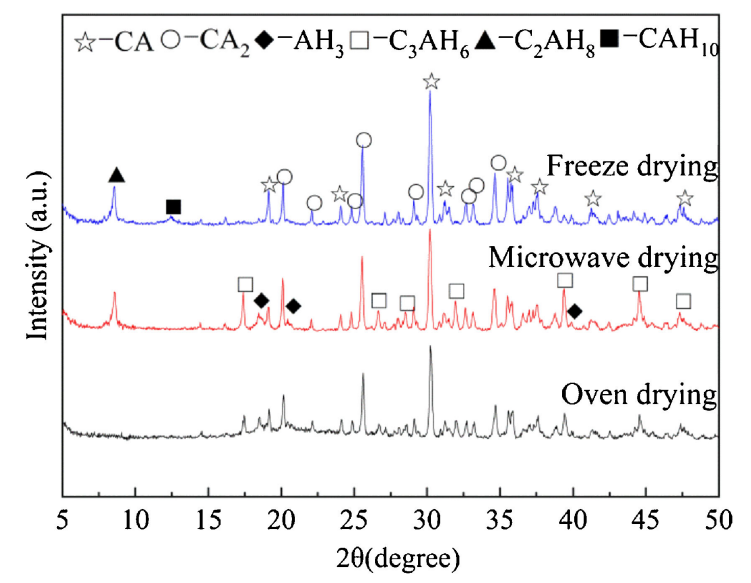

Fig. 1. XRD patterns of cured CAC pastes after drying. 


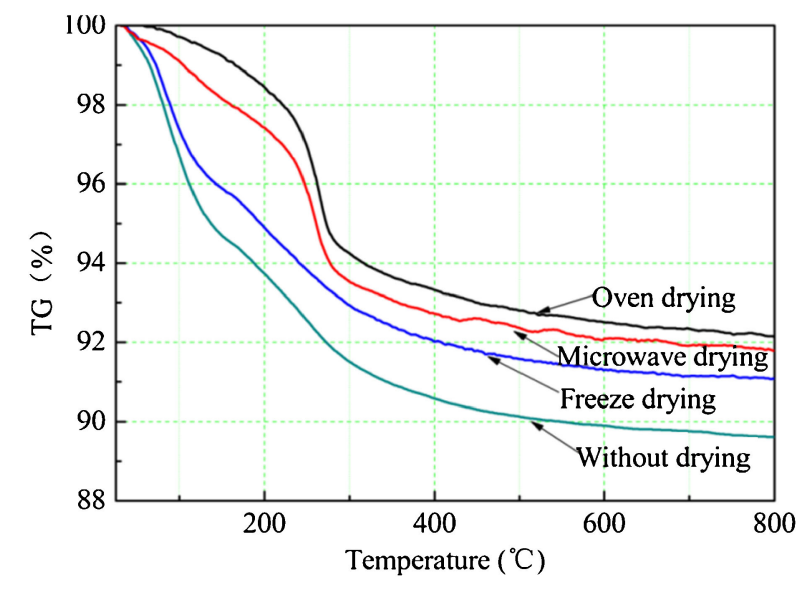

Fig. 2. TG curves of cured CAC pastes after drying.

Table 2. Weight loss of dried pastes at different temperature ranges

\begin{tabular}{lccccr}
\hline & \multicolumn{5}{c}{ Weight loss (wt.\%) } \\
\cline { 2 - 6 } Drying Method & $30-$ & $100-$ & $220-$ & $350-$ & Total \\
& $100^{\circ} \mathrm{C}$ & $220^{\circ} \mathrm{C}$ & $350^{\circ} \mathrm{C}$ & $800^{\circ} \mathrm{C}$ & \\
\hline Without drying & 3.36 & 3.38 & 2.32 & 1.32 & 10.38 \\
Freeze drying & 2.68 & 2.88 & 2.05 & 1.31 & 8.92 \\
Microwave drying & 0.91 & 2.07 & 3.95 & 1.27 & 8.20 \\
Oven drying & 0.29 & 1.69 & 4.38 & 1.50 & 7.86 \\
\hline
\end{tabular}

tion peaks of hydrate phases $\mathrm{CAH}_{10}$ and $\mathrm{C}_{2} \mathrm{AH}_{8}$ in the pastes treated by freeze drying, which confirms that the transformation of metastable hydration products is inhibited under the low temperature drying condition. The XRD patterns of pastes treated by microwave method presents the diffraction peaks of $\mathrm{C}_{2} \mathrm{AH}_{8}, \mathrm{C}_{3} \mathrm{AH}_{6}$ and $\mathrm{AH}_{3}$, which shows that $\mathrm{CAH}_{10}$ and $\mathrm{C}_{2} \mathrm{AH}_{8}$ hydrates are partly transformed to $\mathrm{C}_{3} \mathrm{AH}_{6}$ and $\mathrm{AH}_{3}$ during microwave drying process. There is still some $\mathrm{C}_{2} \mathrm{AH}_{8}$ in the microwave dried pastes, and amorphous $\mathrm{AH}_{x}$ tends to crystallize gradually. Only $\mathrm{C}_{3} \mathrm{AH}_{6}$ and $\mathrm{AH}_{3}$ hydrates present in the oven dried pastes, indicating that the metastable hydrates are completely converted into stable phases after conventional drying.

Figure 2 shows the TG curves of the pastes treated by different drying methods. TG curves of the pastes after non-drying and freeze drying have shown similar variation tendency, while those pastes with microwave drying and conventional drying have shown similar changing trend. The weight loss rate in different temperature range is shown in Table 2. The main weight loss temperature of undried and freeze-dried pastes is in the range of 30$170^{\circ} \mathrm{C}$, while the main weight loss temperature of microwave and oven dried pastes is between $220-300^{\circ} \mathrm{C}$. ${ }^{4)-7)}$ With the total weight loss of pastes decreasing, the treated methods are used from non-drying, freeze drying, microwave drying to oven drying respectively. The DSC curves of the pastes treated by different drying methods are shown in Fig. 3. There is a large endothermic peak at $88^{\circ} \mathrm{C}$ in the undried and freeze dried pastes, corresponding to the



Fig. 3. DSC curves of cured CAC pastes after drying.

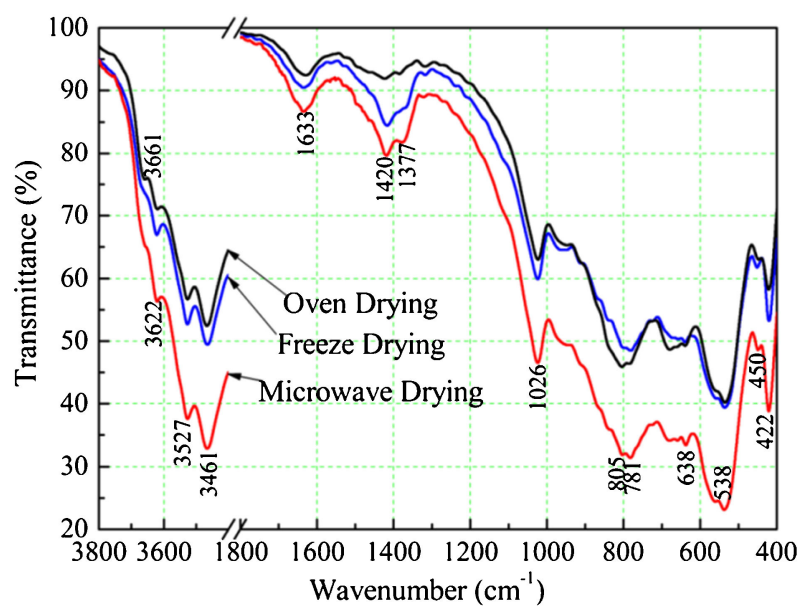

Fig. 4. FTIR spectrums of cured CAC pastes after drying.

removal of free water and the decomposition of $\mathrm{CAH}_{10}$ and $\mathrm{AH}_{x}$ gel. $^{20)}$ There is a small endothermic peak at about $110^{\circ} \mathrm{C}$ in the microwave dried pastes, probably because of the decomposition of $\mathrm{C}_{2} \mathrm{AH}_{8}$. The DSC curves of microwave and oven dried pastes appear a larger endothermic peak at about $265^{\circ} \mathrm{C}$, corresponding to the decomposition of $\mathrm{C}_{3} \mathrm{AH}_{6}$ and $\mathrm{AH}_{3}{ }^{24)-28)}$

The FTIR spectrums of cured CAC pastes after drying are shown in Fig. 4. The weak band at $3661 \mathrm{~cm}^{-1}$ can be assigned to $\mathrm{OH}$ stretching vibration of hydrogarnet $\mathrm{C}_{3} \mathrm{AH}_{6}$ in the oven dried pastes. Higher intensity bands attributed to $\mathrm{OH}$ stretching vibration of gibbsite $\mathrm{AH}_{3}$ can be observed at 3622,3527 and $3461 \mathrm{~cm}^{-1}$ in all samples. The FTIR spectrums of $\mathrm{CAH}_{10}$ and $\mathrm{C}_{2} \mathrm{AH}_{8}$ show similarities with each other, which might be expected from their common hexagonal plate-type structures, but their spectrums are obviously different from that of $\mathrm{C}_{3} \mathrm{AH}_{6}$ which is in accordance with the structural formulation $\mathrm{Ca}_{3}\left[\mathrm{Al}(\mathrm{OH})_{6}\right]_{2}$ for cubic hydrogarnet. So the frequency corresponding to $\mathrm{H}_{2} \mathrm{O}$ deformational mode located at $1640 \mathrm{~cm}^{-1}$ might disappear. Compared with the other two drying methods treated pastes, the peak position at $1633 \mathrm{~cm}^{-1}$ of $\mathrm{OH}$ bending vibration for $\mathrm{H}_{2} \mathrm{O}$ in the oven dried pastes becomes weaker, which indicates that the $\mathrm{CAH}_{10}$ and $\mathrm{C}_{2} \mathrm{AH}_{8}$ have 
been transformed to the stable hydrates. The bands at 1026, 781 and $805 \mathrm{~cm}^{-1}$ are $\mathrm{OH}$ bending vibration for $\mathrm{AH}_{3}$, while the band at $638 \mathrm{~cm}^{-1}$ is $\mathrm{AlO}_{6}$ vibration of $\mathrm{AH}_{3}$. Gibbsite bands eventually obscure characteristic band of $\mathrm{CAH}_{10}$. The bending vibration of $\mathrm{AlO}_{6}$ for $\mathrm{C}_{3} \mathrm{AH}_{6}$ is at $538 \mathrm{~cm}^{-1}$. $^{29)-32)}$ The FTIR spectroscopy is a very useful and straightforward technique to identify the phases coexisting in the cured CAC pastes after drying, and the results are verified with XRD patterns.

\subsection{Microstructure and pore structure of pastes treated by different drying methods}

The microstructure images of cured CAC pastes after drying combined with the energy spectrum analysis are shown in Fig. 5. A large number of short columnar or rodlike hydration products can be observed in the pastes after oven drying, which should be the hydrates $\mathrm{AH}_{3}$ according to energy spectrum analysis, formed by the transformation of metastable phases $\left(\mathrm{CAH}_{10}, \mathrm{C}_{2} \mathrm{AH}_{8}\right.$ and $\mathrm{AH}_{x}$ gel). Flake crystals are mainly formed in the pastes after freeze drying and microwave drying, and the energy spectrum analysis shows those are $\mathrm{C}_{2} \mathrm{AH}_{8}$. The sheets of $\mathrm{C}_{2} \mathrm{AH}_{8}$ adhere to each other in the pastes after freeze drying while there is a certain gap between sheets in the microwave dried pastes. The most likely explanation is that the crystallizing degree of $\mathrm{C}_{2} \mathrm{AH}_{8}$ is higher in the microwave dried pastes. In addition, continuous accumulation of layered hydrates can be observed in the freeze-dried pastes, which is verified to be $\mathrm{CAH}_{10}$ according to energy spectrum analysis.

The apparent porosity of dried pastes is shown in Fig. 6. Among them, the porosity of pastes dried by microwave is the largest, and that of pastes dried by freezing is the smallest. The pores are produced with the transforming of metastable phases to the stable ones. Therefore, the apparent porosity of the pastes dried by oven and microwave is bigger.

The pore volume accumulation and pore size distribution of cured CAC pastes after drying are shown in Figs. 7 and 8 respectively. Pores of different sizes can be classified as gel pore, transition pore, capillary pore and macropore. ${ }^{33)}$ The proportion of various kinds of pores is shown in Table 3. There are more macropores in the pastes after oven drying, accounting for $76.69 \%$. During microwave drying, many capillary pores and transition pores are left in the pastes. The pore size in the range of $20-2000 \mathrm{~nm}$ account for about $85 \%$, and the pore size distribution is relatively uniform. This particular pore distribution is due to the rapid drying of microwaves. The proportion of gel pores in freeze-dried pastes is the largest compared with that of the other two drying methods. It indicates that there is more $\mathrm{AH}_{x}$ gel in the freeze-dried pastes, and $\mathrm{AH}_{x}$ gel does not convert to gibbsite with higher crystallization degree during the drying process. However, free water in the cured pastes froze during freeze drying process, causing volume expansion, which may further lead to pore coarsening. Finally, the proportion of macropores becomes larger in the freeze-dried pastes.
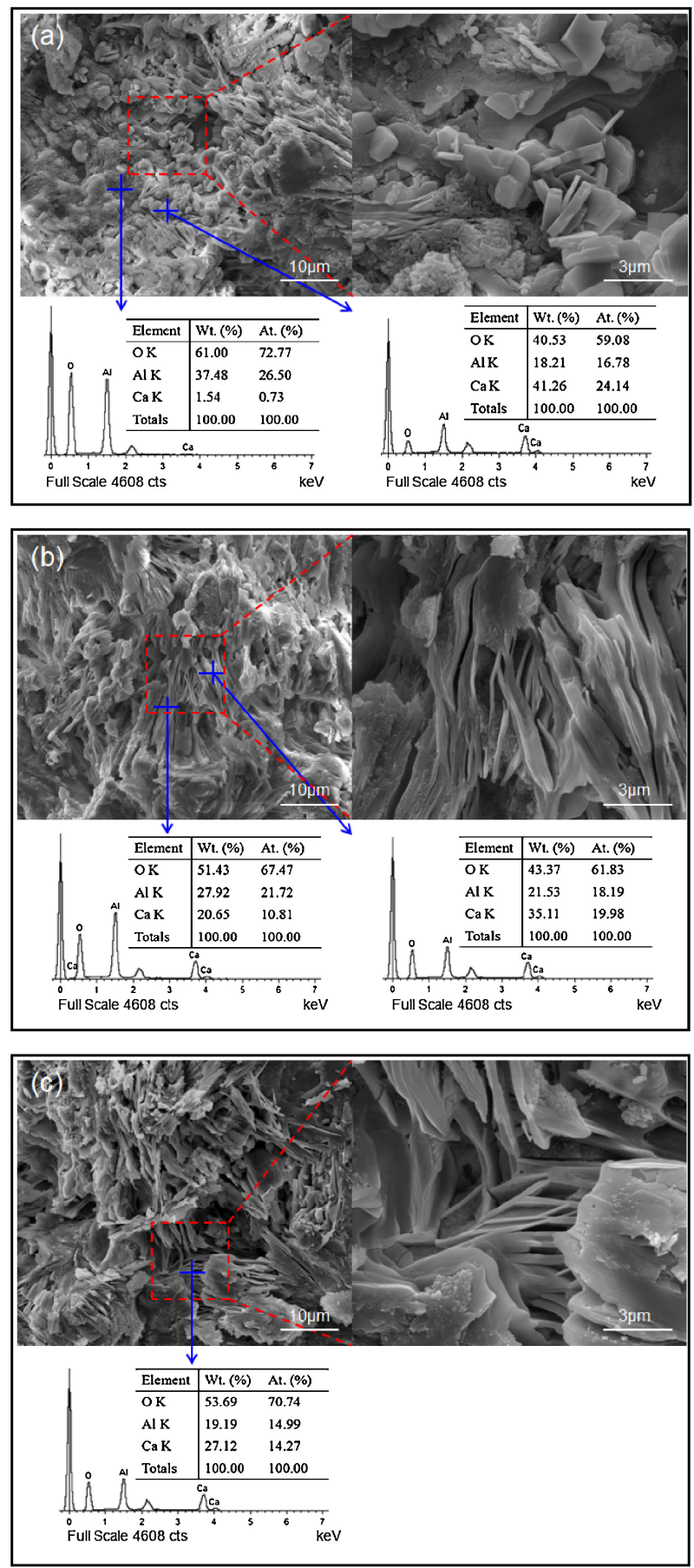

Fig. 5. SEM images and EDS analysis of cured CAC pastes after drying. (a) Oven drying, (b) Freeze drying, (c) Microwave drying.

\subsection{The elastic modulus of pastes treated by different drying methods}

The elastic modulus of pastes treated by different drying methods is shown in Fig. 9. The elastic modulus of freezedried pastes is the highest, while that of microwave dried pastes is the lowest. On the one hand, the $\mathrm{C}_{2} \mathrm{AH}_{8}$ and $\mathrm{CAH}_{10}$ hydration products transform to stable phases and pores are formed during microwave drying process. On the other hand, the water evaporates quickly due to the high heating rate. The vapor cannot release in a short time 


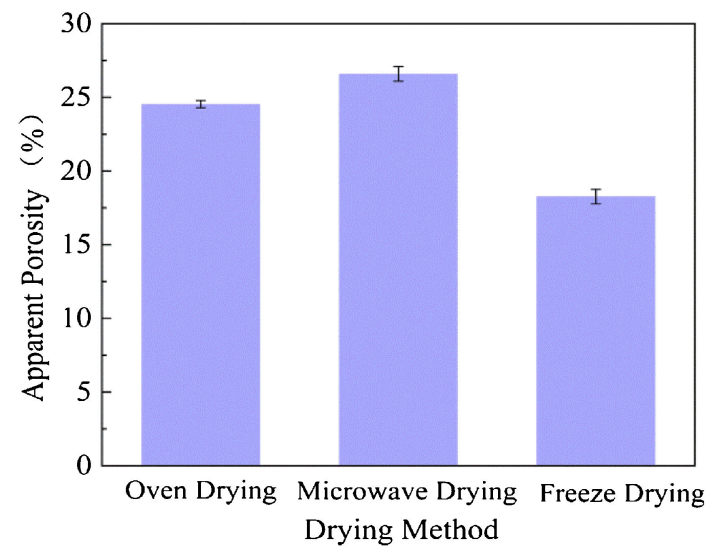

Fig. 6. Apparent porosity of cured CAC pastes after drying.

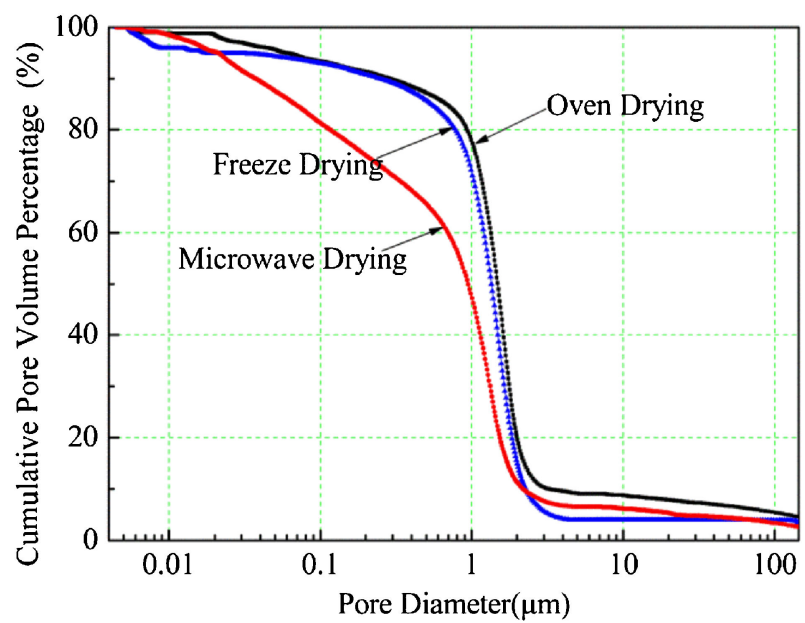

Fig. 7. Cumulative pore volume of cured CAC pastes after drying.

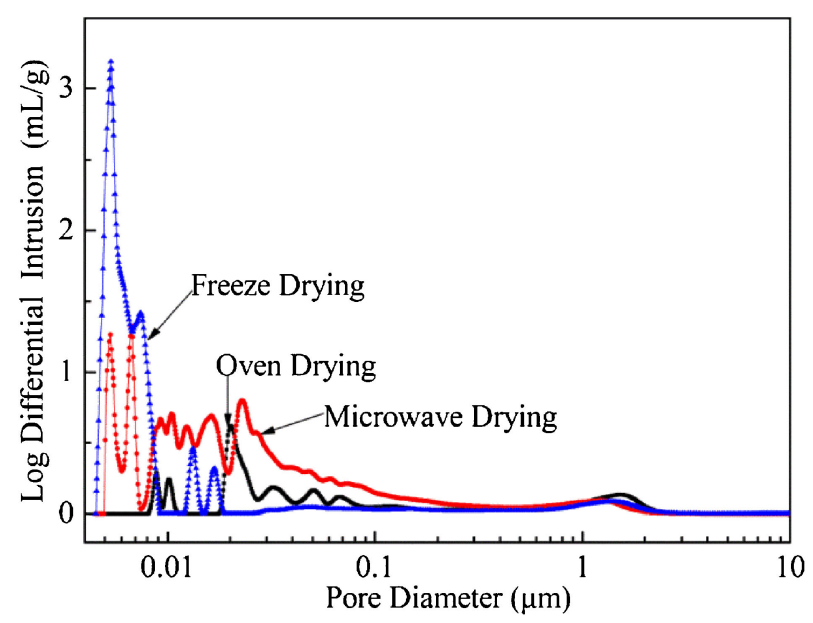

Fig. 8. Differential pore volume of cured CAC pastes after drying.

and a high pressure is formed inside the pastes, leading the generation of cracks in the structure of dried pastes. Although the transformation of metastable phases present in the oven dried pastes, the crystallinity of the newly formed phase is relatively high, which reduce the influence of phase transformation on the structure of dried pastes.
Table 3. Proportion of pores with different size in dried pastes

\begin{tabular}{lcrcc}
\hline \multirow{2}{*}{$\begin{array}{c}\text { Classification } \\
\text { of pores }\end{array}$} & \multirow{2}{*}{$\begin{array}{c}\text { Pore diameter } \\
(\mathrm{nm})\end{array}$} & \multicolumn{3}{c}{ Proportion of pore volume $(\%)$} \\
\cline { 3 - 5 } & & $\begin{array}{c}\text { Oven } \\
\text { drying }\end{array}$ & $\begin{array}{c}\text { Microwave } \\
\text { drying }\end{array}$ & $\begin{array}{c}\text { Freeze } \\
\text { drying }\end{array}$ \\
\hline Gel pore & $<10$ & 1.12 & 1.49 & 4.89 \\
Transition pore & $10-100$ & 5.55 & 17.24 & 2.16 \\
Capillary pore & $100-1000$ & 16.64 & 34.09 & 21.81 \\
Macropore & $>1000$ & 76.69 & 47.18 & 71.14 \\
\hline
\end{tabular}

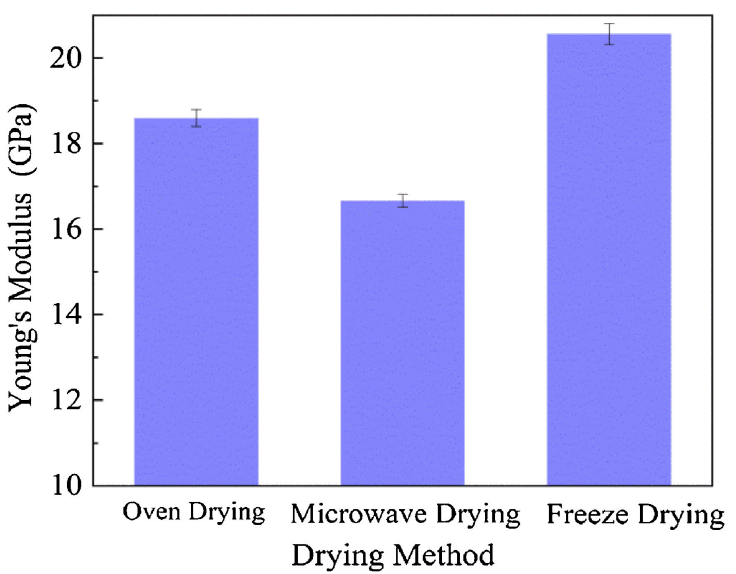

Fig. 9. Young's modulus of cured CAC pastes after drying.

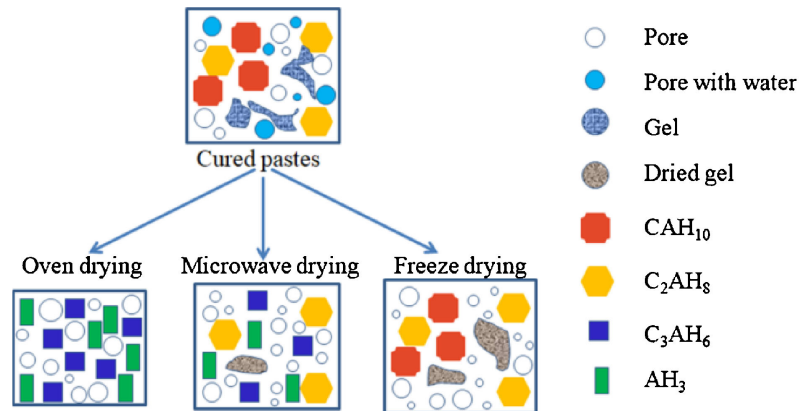

Fig. 10. Schematic diagram of hydrates and pores evolution of cured $\mathrm{CAC}$ pastes during drying process.

The hydration products in the freeze-dried pastes do not change significantly. Therefore, the elastic modulus of the freeze-dried pastes is the largest.

The hydrates and pores evolution processes of cured CAC pastes during drying process are shown in Fig. 10. Mainly, there are three forms (free water, adsorbed water and bound water) of water in the cured pastes. Chemically bound water is firmly combined in the hydrates structure via chemical bond. The physically adsorbed water is held by capillary tension or hydrogen bond on the surface of the hydration products or inside the molecular layers of the colloidal particle. The water that does not participate in the hydration reaction and fills in larger pores of the material is called free water. ${ }^{4), 11)}$ Different forms of water are removed via various drying methods due to binding strength. Freeze drying is carried out at lower temperature, so that the metastable phases almost do not transform. Only free water and physically adsorbed water are removed. As a result, it has little influence on the structure of the pastes. 
In the process of microwave drying, microwave is absorbed by water molecule inside the pastes. Then, the polarization of water molecule occurs, and the collision and friction of water molecule are produced in alternating electric field, resulting in the transformation of microwave energy into heat. The whole pastes are heated uniformly in a relatively short time (just $5 \mathrm{~min}$ in the experiment). The free water and water produced by the transformation of metastable phases is removed at the same time. Based on the XRD results, all of the $\mathrm{CAH}_{10}$ is transformed into stable phases according to Eq. (1), while only part of the $\mathrm{C}_{2} \mathrm{AH}_{8}$ is transformed into stable phases according to Eq. (2) because of short drying time. The pore structure is changed with the transformation of metastable phases. The amorphous $\mathrm{AH}_{x}$ crystallizes in the form of gibbsite together with the gel pore coarsening. Due to the high heating rate, the water evaporates quickly and the drying time is very short, causing part of the metastable phases fails to convert. Therefore, there are many capillary pores and transition pores in the pastes after microwave drying. The free water, physically adsorbed water and part of chemically bound water released from the transformation of metastable phases are removed.

$$
\begin{aligned}
& 2 \mathrm{CAH}_{10} \rightarrow \mathrm{C}_{2} \mathrm{AH}_{8}+\mathrm{AH}_{3}+9 \mathrm{H} \\
& 3 \mathrm{C}_{2} \mathrm{AH}_{8} \rightarrow 2 \mathrm{C}_{3} \mathrm{AH}_{6}+\mathrm{AH}_{3}
\end{aligned}
$$

In the conventional drying process, the samples are heated by heat conduction from the outside to the inside, while the water vapor needs to escape from the inside to the outside. It takes a long time to remove the water in the pastes completely. The metastable phases are completely converted to the stable ones through Eqs. (1) and (2) during the drying process under the action of temperature and time. The densities of $\mathrm{C}_{2} \mathrm{AH}_{8}, \mathrm{CAH}_{10}, \mathrm{C}_{3} \mathrm{AH}_{6}$ and $\mathrm{AH}_{3}$ are $1.72,1.95,2.52$ and $2.42 \mathrm{~g} / \mathrm{cm}^{3}$ respectively. ${ }^{5), 9), 17)}$ Due to the smaller density of metastable phases, the transformation of metastable phases will lead to the increase of porosity and pore size, as well as volume shrinkage in the pastes treated by oven drying.

\section{Conclusion}

Different drying methods (conventional, microwave and freeze drying) are used to remove water in the cured $\mathrm{CAC}$ pastes. The metastable phases $\left(\mathrm{CAH}_{10}, \mathrm{C}_{2} \mathrm{AH}_{8}\right)$ are completely transformed into stable phases $\left(\mathrm{C}_{3} \mathrm{AH}_{6}, \mathrm{AH}_{3}\right)$ in the conventional dried pastes. However, a small amount of $\mathrm{C}_{2} \mathrm{AH}_{8}$ remains unchanged in the pastes dried via microwave due to the high drying rate and short drying time, which means that the hydrates $\mathrm{CAH}_{10}$ and $\mathrm{C}_{2} \mathrm{AH}_{8}$ are partly transformed to $\mathrm{C}_{3} \mathrm{AH}_{6}$ and $\mathrm{AH}_{3}$. Because of the low temperature drying condition, the metastable hydration products do not change obviously after freeze drying. The main hydrates in the freeze-dried pastes are $\mathrm{CAH}_{10}$ and $\mathrm{C}_{2} \mathrm{AH}_{8}$, which confirms that the transformation of hydration products is inhibited during freeze drying process. The morphology of $\mathrm{C}_{2} \mathrm{AH}_{8}$ formed is in the shape of sheets, while $\mathrm{AH}_{3}$ and $\mathrm{C}_{3} \mathrm{AH}_{6}$ are mostly short column and granular respectively.
The porosity of dried CAC pastes increases after oven drying, and there are more macropores in the oven dried pastes. Nevertheless, the pores of CAC pastes treated by microwave are mainly distributed in the range of 20 $2000 \mathrm{~nm}$, while the freeze-dried pastes contain more gel pores and show higher elastic modulus with lower porosity. The effect of freeze drying on the structure of dried pastes is not obvious. Non-conventional drying methods can be used effectively to control the transformation process of metastable phases, adjust the pore structure of the material, and then affect the physical properties of the CAC bonded materials.

Acknowledgments The present work was supported by National Natural Science Foundation of China (grant numbers U20A20239 and 51672195), and the Special Project of Central Government for Local Science and Technology Development of China Hubei Province (grant number 2019 zyyd076).

\section{References}

1) S. Nicolas, H. Jean-François, L. Vincent, B. Yves, M. Pierre and P. Jacques, Cement Concrete Res., 30, 15971607 (2000). doi:10.1016/S0008-8846(00)00342-2

2) B. Pacewska, M. Nowacka, V. Antonovič and M. Aleknevičius, J. Therm. Anal. Calorim., 109, 717-726 (2012). doi:10.1007/s10973-012-2233-6

3) B. Han, P. Wang, C. Ke, W. Yan, Y. Wei and N. Li, Cement Concrete Res., 79, 257-264 (2016). doi:10. 1016/j.cemconres.2015.09.019

4) M. A. Maaroufi, A. Lecomte, C. Diliberto, O. Francy and P. L. Brun, J. Eur. Ceram. Soc., 35, 1637-1646 (2015). doi:10.1016/j.jeurceramsoc.2014.11.029

5) A. P. Luz and V. C. Pandolfelli, Ceram. Int., 38, 14171425 (2012). doi:10.1016/j.ceramint.2011.09.021

6) S. M. Park, J. G. Jang, H. M. Son and H. K. Lee, J. $\mathrm{CO}_{2}$ Util., 21, 224-226 (2017). doi:10.1016/j.jcou.2017. 07.002

7) C. Parr, F. Simonin, B. Touzo, C. Wohrmeyer and A. Namba, J. Tech. Asso. Refract., 25, 78-88 (2005). http:// www.secar.net/documents/TP_GB_RE_LAF_043.pdf

8) F. Wang, P. Chen, X. Li and B. Zhu, Materials, 11, 1849 (2018). doi:10.3390/ma11101849

9) M. P. Adams and J. H. Ideker, Cement Concrete Res., 100, 284-296 (2017). doi:10.1016/j.cemconres.2017. 07.007

10) M. Nouri-Khezrabad, A. P. Luz, V. R. Salvini, F. Golestani-Fard, H. R. Rezaie and V. C. Pandolfelli, Ceram. Int., 41, 3051-3057 (2015). doi:10.1016/ j.ceramint.2014.10.143

11) N. C. Collier, J. H. Sharp, N. B. Milestone, J. Hill and I. H. Godfrey, Cement Concrete Res., 38, 737-744 (2008). doi:10.1016/j.cemconres.2008.02.012

12) B. Lothenbach, L. Pelletier-Chaignat and F. Winnefeld, Cement Concrete Res., 42, 1621-1634 (2012). doi:10. 1016/j.cemconres.2012.09.002

13) F. A. Cardoso, M. D. M. Innocentini, M. M. Akiyoshi and V. C. Pandolfelli, J. Eur. Ceram. Soc., 24, 20732078 (2004). doi:10.1016/S0955-2219(03)00371-6

14) T. Matusinović, J. Šipušić and N. Vrbos, Cement Concrete Res., 33, 1801-1806 (2003). doi:10.1016/ 
S0008-8846(03)00201-1

15) A. Ramezani, M. M. Mohebi and A. Souri, J. Mater. Eng. Perform., 22, 1010-1017 (2013). doi:10.1007/ s11665-012-0389-7

16) C. Gosselin, E. Gallucci and K. Scrivener, Cement Concrete Res., 40, 1555-1570 (2010). doi:10.1016/ j.cemconres.2010.06.012

17) V. Antonoviča, J. Kerienèb, R. Borisa and $M$. Alekneviius, Procedia Engineer., 57, 99-106 (2013). doi:10.1016/j.proeng.2013.04.015

18) E. Knapen, O. Cizer, K. V. Balen and D. V. Gemert, Constr. Build. Mater., 23, 3431-3438 (2009). doi:10. 1016/j.conbuildmat.2009.06.004

19) M. D. M. Innocentini, C. Ribeiro, L. R. M. Bittencourt and V. C. Pandolfelli, J. Am. Ceram. Soc., 84, 26962698 (2001). doi:10.1111/j.1151-2916.2001.tb01073.x

20) A. P. Luz and V. C. Pandolfelli, Ceram. Int., 37, 37893793 (2011). doi:10.1016/j.ceramint.2011.06.034

21) Y. Wang, X. Li, B. Zhu and P. Chen, Ceram. Int., 42, 11355-11362 (2016). doi:10.1016/j.ceramint.2016.04. 058

22) J. Czechowski and I. Majchrowicz, Ceram. Int., 44, 6570 (2018). doi:10.1016/j.ceramint.2017.09.065

23) M. Radoiu, Chem. Eng. Process., 155, 108088 (2020). doi:10.1016/j.cep.2020.108088

24) B. Pacewska and M. Nowacka, J. Therm. Anal. Calorim., 117, 653-660 (2014). doi:10.1007/s10973014-3804-5
25) F. Guirado, S. Galí and J. S. Chinchón, Cement Concrete Res., 28, 381-390 (1998). doi:10.1016/ S0008-8846(98)00007-6

26) N. Ukrainczyk, T. Matusinovic, S. Kurajica, B. Zimmermann and J. Sipusic, Thermochim. Acta, 464, 7-15 (2007). doi:10.1016/j.tca.2007.07.022

27) B. Zhu, B. Fang and X. Li, Ceram. Int., 36, 2493-2498 (2010). doi:10.1016/j.ceramint.2010.07.007

28) M. D. M. Innocentini, F. A. Cardoso, M. M. Akiyoshi and V. C. Pandolfelli, J. Am. Ceram. Soc., 86, 11461148 (2004). doi:10.1111/j.1151-2916.2003.tb03438.x

29) A. H. Lopez, J. L. G. Calvo, J. G. Olmo, S. Petit and M. C. Alonso, J. Am. Ceram. Soc., 91, 1258-1265 (2010). doi:10.1111/j.1551-2916.2008.02283.x

30) A. Fernández-Jiménez, Á. Palomo and T. Vazquez, J. Am. Ceram. Soc., 91, 1231-1236 (2008). doi:10.1111/ j.1551-2916.2007.02002.x

31) A. Fernández-Jiménez, T. Vázquez and A. Palomo, J. Am. Ceram. Soc., 94, 1297-1303 (2011). doi:10. $1111 / \mathrm{j} .1551-2916.2010 .04242 . x$

32) M. A. Trezza and A. E. Lavat, Cement Concrete Res., 31, 869-872 (2001). doi:10.1016/S00088846(01)00502-6

33) R. Kumar and B. Bhattacharjee, Cement Concrete Res., 33, 155-164 (2003). doi:10.1016/S00088846(02)00942-0

34) H. Taira and H. Nakamura, Refract., 158, 10-17 (2010). 